\title{
OBSERVATIONS ON MENSTRUATION AND PREGNANCY AMONG FEMALE SPINAL CORD INJURY PATIENTS
}

\author{
By A. Estin Comarr, M.B., M.D., F.A.C.S., F.I.C.S., D.A.B. \\ Spinal Cord Injury Service, Veterans Administration Hospital, Long Beach, California; \\ the Urology Service, Rancho Los Amigos Hospital,Downey, California; and the Department \\ of Urology, School of Medicine, Loma Linda University
}

MENSES and pregnancies among females with spinal cord injury have been alluded to by Gerstmann (I926), Bors et al. (1950), Cooper and Hoen (I952), Talbot (1955), Bradley (1956), Bors (1957), Bors and Comarr (1960), and Jung and Schmidt (1962). Robertson and Guttmann (1963) published an excellent summary of their experiences with pregnancy among female spinal cord injury patients.

The purpose of this communication is to report the results of a survey conducted among the available female patient both at Rancho Los Amigos Hospital, Downey, California, and at the Long Beach Veterans Administration Center. An attempt was made to ascertain (I) how long it took for menses to return after spinal cord injury, and (2) the effect of pregnancy upon the upper urinary tract.

\section{SURVEY ON MENSES}

Twenty-five female patients were interrogated about their menstrual periods (Table I).

Five patients had complete neurological lesions in the cervical segments of the spinal cord. The ages at time of injury ranged from $I 7$ to 28 . Three did not miss a period after injury; one patient missed three periods; and one patient missed seven periods. The periods were regular before and after among four patients. One patient had irregular periods prior to injury which became regular after injury. Two patients had dysmenorrhoea before injury which improved to only minimal discomfort after injury. These five patients had positive rectal tone on rectal examination.

Nine patients had incomplete neurological lesions of the cervical segments of the spinal cord. The ages at time of injury ranged from $I 7$ to 42 . Four patients did not miss a period after injury; one patient missed one period; one patient missed six periods; one patient missed seven periods; one patient missed I 6 periods; and one patient missed 30 periods. The menses were regular before and after injury in eight of the patients. One patient had irregular menses before injury which became regular after injury. Four patients had dysmenorrhoea before injury which improved to minimal discomfort after injury. These nine patients had positive rectal tone on rectal examination.

Three patients had complete neurological lesions between the first and sixth thoracic segments of the spinal cord. The ages at time of injury ranged from 19 to 34. One patient did not miss a period after injury; one patient missed two periods; and one patient missed three periods. The menses were regular before and after injury in two of the patients. One patient had regular menses before injury which became irregular after injury. These three patients had positive rectal tone on rectal examination.

Six patients had complete neurological lesions between the seventh and twelfth thoracic segments of the spinal cord. The ages at time of injury ranged from 18 


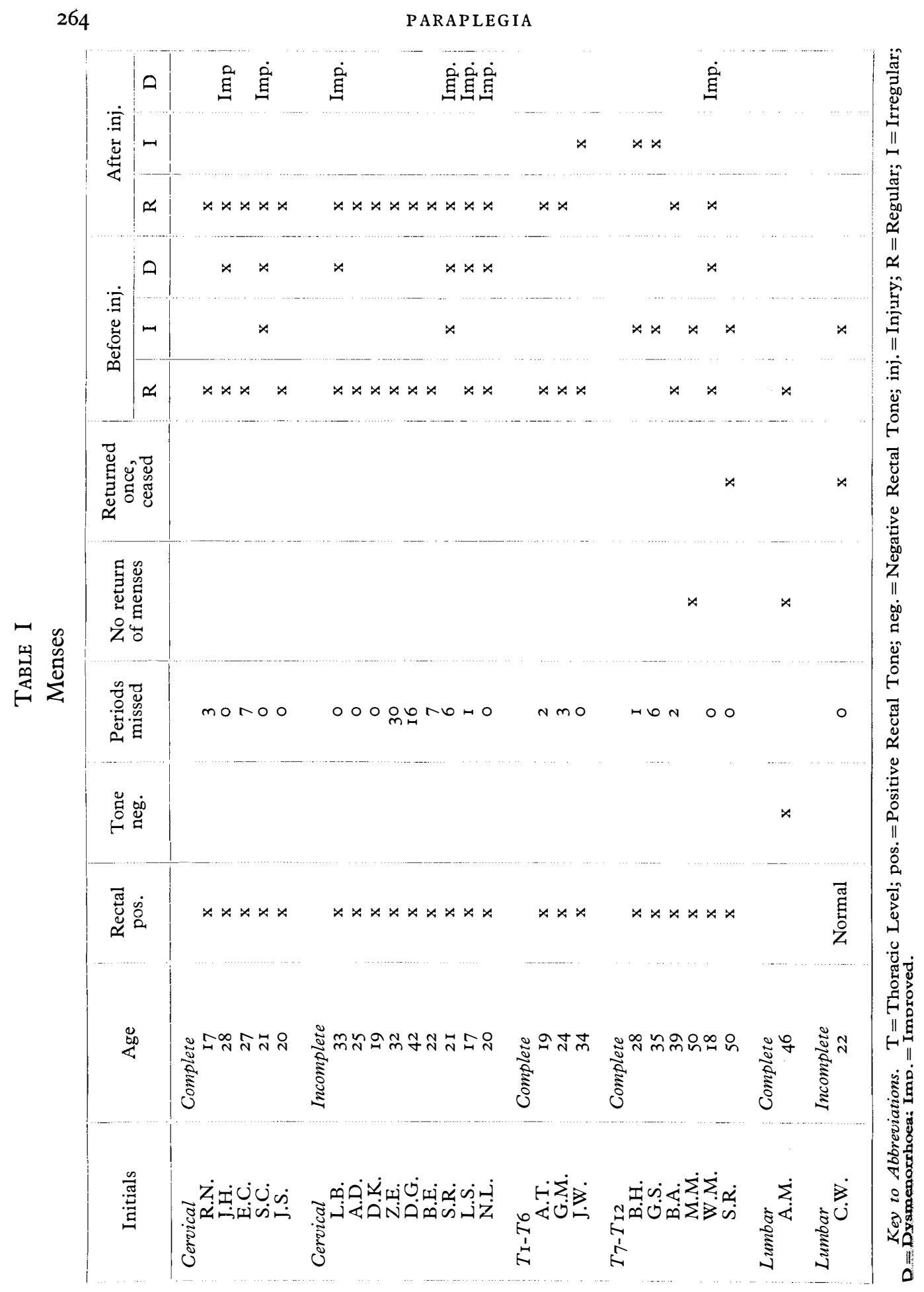


to 50. One 50-year-old patient had irregular periods as part of her menopause prior to injury; after injury she had no return of her menses. Another 50-year-old patient at time of injury was also in her climacteric period of life prior to injury; after injury she had one period and none thereafter; one patient did not miss a period; one patient missed one period; one patient missed two periods; and one patient missed six periods. Two patients had regular periods before and after injury. Two patients had irregular menses before and after injury. One patient had dysmenorrhoea before injury which improved to only minimal discomfort after injury. These six patients had positive rectal tone on rectal examination.

One 46-year-old patient had a complete neurological lesion in the lumbar segments of the spinal cord. She had had regular menses prior to injury which were abolished after injury. She was the only patient in this series of 25 who showed absent rectal tone on rectal examination.

One 22-year-old patient had an incomplete neurological lesion in the lumbar segments of the spinal cord. She had a normal period which began three days after injury and was of normal duration; following this period she had not had another period when questioned six months later. Because of sacral sparing this patient has a normal control of her bladder and rectal sphincters.

Comments. Rectal examinations were performed on each patient in order to ascertain whether the reflex arcs through the sacral segments were or were not intact. The author wanted to see if the presence or absence of this reflex activity would play a role on the return of menses after injury. Only one patient in this series had an absence of reflex activity through the conus medullaris and, therefore, this question could not be answered; unfortunately, her menses could not have returned because she was in her climacteric state of life when injured.

Observations on two female patients with traumatic cord lesions (not included in the above series) who have had subarachnoid alcohol injections after injury, creating areflexia through the conus medullaris, would indicate that the menses do return in these patients after injury. One patient who at age 30 sustained a segmentally complete lesion at thoracic eight had marked dysmenorrhoea and irregularity of her menses before injury. Following the injury the dysmenorrhoea was markedly improved but the irregularity of the periods persisted. The irregularity persisted even after the subarachnoid alcohol injection which was given for somatic spasticity. Another patient with a segmentally complete lesion at thoracic four had a subarachnoid alcohol block after injury for spasticity; this did not alter the regularity of her menses.

A patient with a complete lesion and functionally contracted bladder from arachnoiditis, also not included in this series, did not lose a single period following subarachnoid alcohol injection. The regularity of the menses also persisted.

The two patients who required 16 and 30 months for a return of their menses had incomplete cervical lesions; the one who required I 6 months was 42 years of age; the one who required 30 months was 32 years of age. Both patients had a spontaneous return of their menses without hormonal therapy. The 42-year-old patient stated that prior to the return she explained the absence of menses as part of menopause since she had had 'hot flashes' prior to the return. With the arrival of the menses the menopausal symptoms disappeared and she has since been as regular as before injury.

Dysmenorrhoea was markedly improved after injury in every female who had 
been troubled with this symptom prior to injury. The completeness or incompleteness of this lesion played no role. Again, there were too few patients in the lumbar group to show whether this played a role. One patient described the improvement of dysmenorrhoea after injury as 'I can tell and that's all'.

One patient who sustained a complete lesion at cervical seven at age 27 stated that until the age of 38 she had no difficulty with her menses; however, for the last three years following her 38 th birthday the duration of her menses is shortened; also, three to four days prior to the menses she has symptoms of autonomic hyperreflexia.

One patient described a marked increase in somatic spasticity of her limbs during the menses.

Our findings do not coincide with those of Cooper and Hoen (I962) who stated: 'Following a severe spinal cord injury in young adult females there is a cessation of menstruation for a period of three to six months. In most instances there is a resumption of menstruation after this period, but the menses are much scantier than they had been previously and often occur at irregular intervals.'

Conclusions. From the foregoing one may conclude that:

I. The majority of females of the younger age-group will have a return of their menses within the first six months after injury of which nearly 50 per cent. will not miss a single period.

2. The majority of females who had regularity of menses before will continue in a similar manner after injury.

3. Previously irregular periods may remain irregular after injury or become regular.

4. Dysmenorrhoea will not be a painful experience after injury.

5. Level, completeness or incompleteness of the lesion does not appear to play a role.

6. Presence or absence of reflex arcs through the sacral segments after injury does not appear to play a role.

7. Females who are in the climacteric period of life will probably lose their menses after injury; those approaching the climacteric period may also lose their menses after injury.

\section{SURVEY ON PREGNANCIES}

Four patients were pregnant at time of injury (Table II).

Mrs. E. F. sustained a clinically incomplete lesion at $\mathrm{C}_{5}$ on $2 \mathrm{I} .9 .58$, at age 22. Her pregnancy was judged to be about two months' duration. Prior to injury she had had three normal deliveries. Immediately after injury she was placed on an intraurethral catheter regimen. She had no urinary tract complications throughout the following months and delivered a normal baby (vaginal route) at term. She did not have acute pyelonephritic attacks during her post-natal convalescent period. Her menses did not return for one year post-partum. Two years after injury, because of sacral sparing, she was able to remove the catheter and had nearly normal bladder control; she also had nearly normal rectal control. In August of I962 this patient became pregnant again. Pre- and post-partum periods were not complicated by urological complications. She did not require a catheter at any time. She delivered a normal baby (vaginal route). She is still a wheelchair 

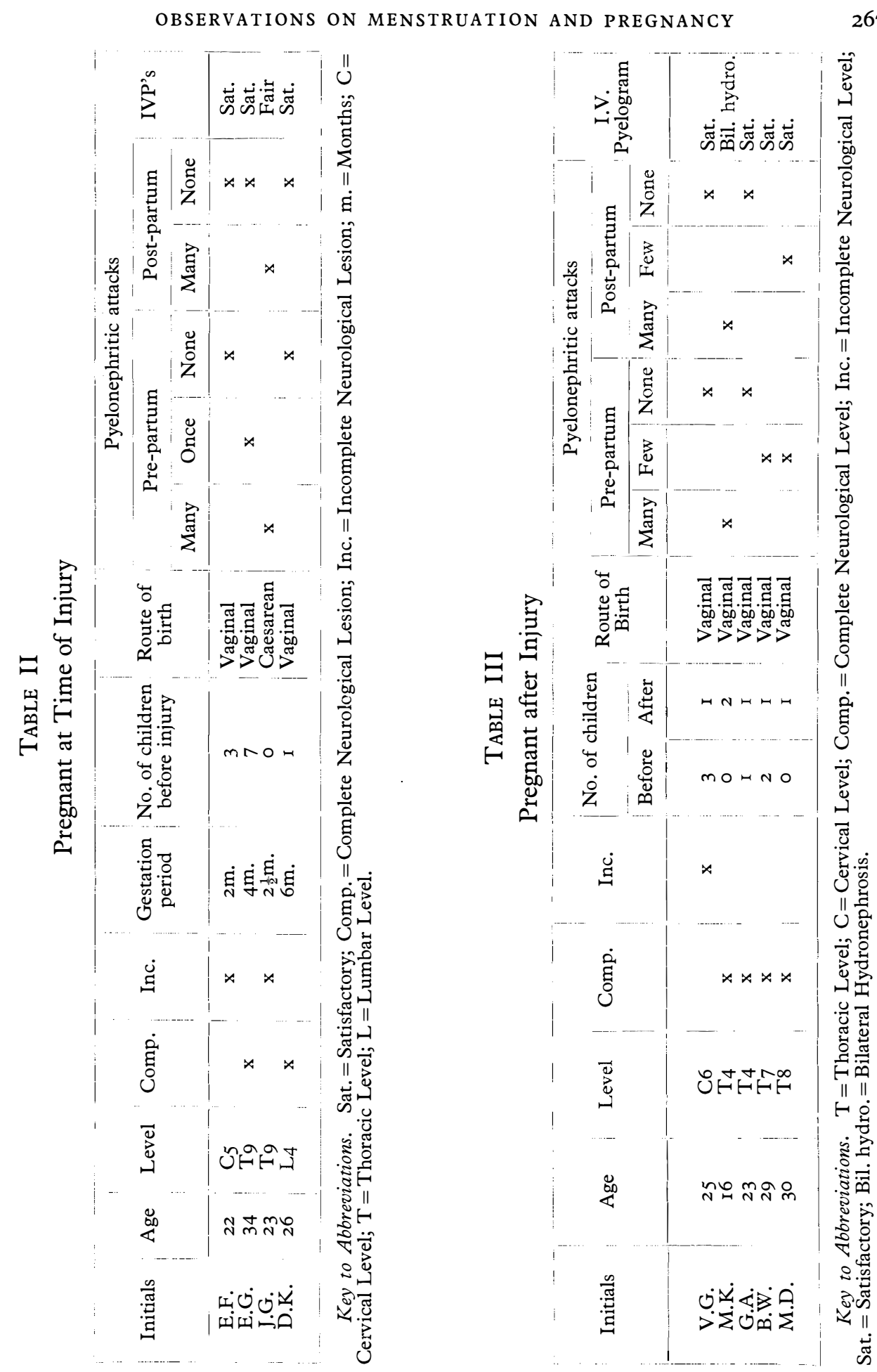
patient. She has adequate time in which to reach the toilet when she has the desire to void. A review of her most recent excretory pyelograms show them to be satisfactory.

The second of the four patients was Mrs. E. G., at age 34; she sustained a clinically complete lesion at T9. Her pregnancy was judged to be about four months' duration. Prior to injury she had had seven normal deliveries. An intraurethral catheter was inserted immediately after injury. At term she developed pains in the lower abdomen and back which were negligible compared to her preinjury pains. She was given a 'sleeper' that evening. When the nurse came to turn her during the night, the infant was found with the mother; a spontaneous delivery had occurred without the knowledge of the mother. This patient had had the intraurethral catheter from time of injury through the post-partum period. Only on one occasion at about six months' gestation did she have what apparently was an acute pyelonephritis which was treated conservatively. She missed only two periods following delivery; this was followed by a hysterectomy. The excretory pyelograms are negative. Since her pregnancy she had attained a balanced upper motor neuron bladder emptied completely only by digital stimulation of the external rectal sphincter. She wears absorbent pads and plastic panties. Further questioning of this patient revealed that the act of coitus does not arouse her but she is 'aroused a lot' by manipulation of her breasts; however, she does not reach a climax.

The third of the four patients, Mrs. J. G., sustained a clinically incomplete lesion at T9, at age 23, on I8.II.55. She was judged to have a I4 to I5 weeks' gestation. This was her first pregnancy. She was placed on an intrauretheral catheter immediately after injury. Between 2I March and 2 July I956 she had about seven attacks of pyelonephritis (Bradley, 1956); on four occasions bilateral ureteral catheters were introduced for a number of days. The last ureteral catheters were introduced on 2 July; on 3 July a normal infant was delivered by a classical Caesarean section. At this time her tubes were ligated; the following day she was afebrile and the ureteral catheters were removed six days after delivery. Eventually the urethral catheter was removed and she voided every one to three hours; she had precipitate micturition. Pyelograms three months post-partum revealed prompt five-minute function with sharp calyceal patterns bilaterally. She had sensory sparing of the sacral segments. On arrival at our Centre in April of 1960 pyelographic reflux was found in the right and her residual urine was elevated; she was placed on an indwelling intraurethral catheter regimen and has faired rather well. Excretory urograms are fair.

The fourth patient, Mrs. D. K., sustained on 4.I.63 a clinically complete lesion at L4; she was 26 years of age at the time of the accident. She was judged to have a six-month pregnancy at the time of injury. She had had one normal delivery prior to injury. Immediately after injury she was placed on an intraurethral catheter regimen. On 22 April 1963 she had a normal delivery. Throughout the entire pre- and post-partum periods she did not have any pyelonephritic attacks. When seen nine months after her delivery, she still had amenorrhoea and was still lactating (Chiari-Frommel syndrome). In July I963 she developed a balanced lower motor neuron bladder.

Five patients became pregnant after injury (Table III).

Mrs. G. A. on 8.I2.5 I, at age 23, sustained a clinically complete lesion at T4. History revealed one normal delivery before injury. Two years after injury she 
attained a balanced upper motor neuron bladder. In I 959 she became pregnant and delivered a normal infant at term (vaginal route). Throughout the pre- and post-partum periods she did not have acute pyelonephritic attacks. Her most recent excretory urograms are satisfactory.

Mrs. B. W. sustained a clinically complete lesion at $\mathrm{T}_{7}$, in November 1958 , at age 29. Immediately after injury an intraurethral catheter was introduced and she remained on this regimen. Prior to injury she had had two normal deliveries and seven miscarriages; with each of these pregnancies she had marked nausea for the first three to four months. Following the injury she missed six periods but was regular thereafter until she became pregnant. She was nauseous most of the nine months and was mostly bedridden the last four months of her pregnancy. During the latter period she had about four attacks of severe acute pyelonephritis which in each instance was treated conservatively with antibiotics. Following the pregnancy she was well and has had no major flare-ups. Following the delivery she had a regular period; a tubal ligation was performed shortly thereafter. Following this surgery her menses stopped and she continued to lactate for two years (ChiariFrommel syndrome). When the lactation spontaneously stopped, the menses returned and have been regular. The excretory pyelograms are very satisfactory.

Mrs. M. D. sustained a segmentally complete lesion at T8 in I945, at age 30. Immediately after injury an intraurethral catheter was introduced and she has remained on this regimen. She delivered a full-term infant about two years after injury. This had been her first pregnancy. She had an uneventful pre- and postpartum period with only a few bladder flare-ups. Since her pregnancy she has had a subarachnoid alcoho! injection and a bilateral oophorectomy. Her excretory pyelograms are essentially satisfactory.

Mrs. M. K. in I943, at age I6, sustained a clinically complete lesion at $\mathrm{T}_{4}$. At age 30 she married and within two years she delivered two children (vaginal route). Regular menstrual periods returned about six weeks after the first birth and about 12 weeks after the second birth. During both pregnancies, pre- and post-partum, she had many acute attacks of pyelonephritis which required ureteral catheterisation and lavage. She now has bilateral hydronephrosis.

Mrs. V. G. in July of I 957 , at age 25 , sustained a clinically incomplete lesion at C6. She had three normal vaginal deliveries before injury. Six months after injury she spontaneously developed a catheter-free state. After injury, at age 28, she delivered vaginally a normal child. She had no attacks of pyelonephritis preor post-partum. Her excretory pyelograms are essentially satisfactory.

Comments. Among the four females that were pregnant at time of injury it is very striking to note that none aborted their pregnancy; two were in the first trimester and two in the second trimester. All levels of injury were represented in this admittedly small group of patients with complete and incomplete lesions.

This group of four showed that of the four females three were delivered vaginally and one by Caesarean section with no untoward results from a gynecological point of view.

The notable fact in this group is that the only patient who had severe difficulty with the upper urinary tract was the patient who had never been pregnant before injury.

The most recent excretory urograms on three of the patients in this series o four were considered satisfactory whereas the pyelograms of the female who had 
never been pregnant before injury were considered only fair. This latter female was originally catheter-free because of sacral sparing; because of vesico-ureteral reflux an intraurethral catheter was introduced at our Centre.

Among the five patients pregnant after injury, two had no previous deliveries; all five were delivered by the vaginal route. Four had complete thoracic lesions and one had an incomplete cervical lesion; three of the five had levels above the sympathetic visceral outflow. The autonomic hyperreflexia noted during the delivery of one of the latter was controlled by hexamethonium chloride (Bors, I964). The other patient can remember that throughout labour and delivery she had a 'horribly severe headache' which subsided only after the delivery; one must assume that the attending physicians were not aware of the autonomic dysreflexia syndrome.

Jung and Schmidt (I962) and Robertson and Guttmann (I963) both describe very well autonomic dysreflexia, which they followed clinically step by step; yet, none described the use of a ganglionic blocking agent even though the pressure was I90/I00 in the case of Robertson and Guttmann when forceps were applied. When the pressure reached 230/I45, preceded by 'dramatic convulsions and profound headaches', Jung and Schmidt used a caesarean section as emergency therapy.

One of the group who had a child before injury had no upper urinary tract difficulties throughout the pregnancy or after. Another patient who had two children before injury had only a few attacks of acute pyelonephritis during the pregnancy but none after delivery. Another female of this group who had no children prior to injury had a few attacks of what she called 'bladder flare-ups' during and after pregnancy. Still another of this group had no children prior to injury. She was injured at I6 married at 30. She delivered two children but had a stormy course before and after pregnancy with both deliveries. Throughout, frequent ureteral catheterisations were required for lavage of both kidneys.

The most recent pyelograms reveal that four of the patients have satisfactory pyelograms; yet, the one patient who had never had children prior to injury with severe pyelonephritis during her pregnancies, now has severe bilateral hydronephrosis.

Reviewing again both groups of females who were pregnant (nine patients) one quickly notices that the female who now has only fair pyelograms and has been placed on intraurethral catheter drainage because of reflux and the female with severe hydronephrosis, were never pregnant before injury. Yet, one cannot dogmatically state that if a female has not been pregnant before injury she should never become pregnant after injury in order to prevent kidney deterioration. One patient who was never pregnant before injury had only a few pyelonephritic attacks before and after delivery and yet her pyelograms are essentially satisfactory. Bors (1964) has seen a female who has delivered five full-term babies, the first was a vaginal delivery, the second, third, fourth and fifth deliveries were by Caesarean. She had no acute pyelonephritic attacks. She had a clinically complete lesion at Tro in I937. Interestingly, she had had no pregnancies prior to injury. The five deliveries were performed without anaesthesia. Her menses have always been regular.

In this series none of the females who had had children prior to injury had much difficulty with urinary tract infection.

In spite of urinary infection none of these patients gave histories of any toxaemias of pregnancy; one might expect the hypertension of pre-eclampsia 
but in concurrence with Robertson and Guttmann (1963) we found none by history.

Conclusions. From the foregoing one may conclude that:

I. Spinal cord injury need not necessarily cause abortion if the female is pregnant at the time.

2. If the female has not had children prior to injury the chances of renal complications appear to be greater if pregnant at time of injury or after injury.

3. The obstetrician must be very much aware of autonomic dysreflexia among these pregnant females as a differential diagnosis of pre-eclampsia even though the latter condition does not appear to have been present among these patients.

4. The philosophy of pregnancy among these spinal cord injury females will probably vary from physician to physician; the physician must consider many factors before he advises pregnancy to a patient of this type.

\section{SUMMARY}

Twenty-five female patients with spinal cord injury were interrogated about their menstrual periods. The following observations were noted: the majority of females had a return of their menses within the first six months after injury; 50 per cent. have not missed a single period; in this series, one patient had a return of menstruation after I6 months and another after 30 months; level and extent of the lesion did not appear to play a role; presence or absence of sacral reflex arcs did not play a role; females who are in or near the climacteric period of life will probably lose their menses; dysmenorrhea ceased to be a painful experience after injury.

Four patients were pregnant at time of injury, and five patients were pregnant after injury. The following observations were noted: none of the patients pregnant at time of injury aborted their pregnancies; all babies were delivered vaginally except one by caesarean section; there were far less renal complications associated with pregnancy among those patients who had children prior to injury; the obstetrician must be aware of autonomic dysreflexia and its management in order to differentiate it from a pre-eclampsia.

\section{RÉSUMÉ}

Une recherche sur la période menstruelle de 25 femmes ayant souffert des lésions de la moëlle épinière avec paraplégie consecutive a donné les suivants résultats:

La majorité des femmes ont eu de nouveau leur menstruation pendant les premiers six mois après l'accident. $50 \%$ n'ont pas eu aucune interruption de leur période menstruelle. Une seule a eu la menstruation après 16 mois et une autre après 30 mois. Le niveau et l'extension de la lésion semble ne pas avoir aucune influence.

La 'presénce ou l'absence de l'arc réflexe sacral n'a pas d'importance. Les femmes qui sont près de leur ménopause auront probablement la ménopause precipitée. La dismenorrhée n'est plus douloureuse après l'accident.

Quatre femmes étaient enceintes au moment de l'accident et cinq femmes sont devenues enceintes après l'accident. Les suivants faits ont été observés: 
Aucune des malades enceintes au momment de l'accident a avorté. Tous les accouchement ont été fait par voie vaginale exception faite par une seule malade qui a eu une césarienne.

Les malades qui ont eu des enfants avant l'accident ont eu moins de complications rénales que les autres.

L'obstetricien doit bien connaître la disréflexie autonomique et son traitement pour pouvoir faire le diagnostic differentiel avec la préeclampsie.

\section{ZUSAMMENFASSUNG}

Fünfundzwanzig Frauen mit traumatischen Querschnittslähmungen wurden hinsichtlich Menstruationsstörungen befragt. Die Majorität hatte ihre 6 Monate nach der Verletzung. In 50\% war die Menstruation nicht unterbrochen. Eine Patientin verblieb I6 Monate amenorrhoisch und eine zweite Patientin hatte keine Menstruation während 30 Monaten. Weder die Lage noch die Ausdehnung der Querschnittsverletzung spielte eine Rolle. Anwesenheit oder Abwesenheit der sakralen Reflexbögen hatte auch keine Bedentung. Frauen im vorklimakterischen Alter werden wahrscheinlich nicht mehr menstruieren. Dysmenorrhoische Schmerzen werden nach Querschnittverletzung verschwinden.

Vier Patientinnen waren zur Zeit der Verletzung schwanger und fünf Patientinnen bekamen schwanger nach dem Unfall. Keine von ihnen abortierte; alle wurden per vias naturales entbunden, abgesehen von einer Patientin, die durch Kaiserschnitt entbunden wurde. Patientinnen, welche Kinder vor der Verletzung geboren hatten, neigten weniger zu Nierenkomplikationen. Der Geburtshelfer muss mit dem Syndrom der autonomen Dysreflexie vertraut sein, um es von der Pre-eklampsie zu unterscheiden.

\section{ACKNOWLEDGEMENT}

The author wishes to express his appreciation to Mrs. Bernice B. Gunderson, R.N., Head Nurse in charge of the Urology Service, Rancho Los Amigos Hospital, Downey, California, for her assistance in this study.

\section{REFERENCES}

Bors, ERnest (I957). Urol. Surv. 7, I77.

Bors, ERNEST (I964). Personal Communication.

Bors, ERnest \& Comarr, A. Estin (i960). Urol. Surv. ro, i9i.

Bors, Ernest, Engle, Earl T., Rosenquist, Robert C. \& Hollinger, Victor H. (I950). F. clin. Endocr. ro, 38I.

Bradley, William S. (I956). Pregnancy in Paraplegia: Urological Complications. Proceedings of the Fifth Annual Clinical Paraplegic Conference, Veterans Administration Hospital, Hines, Illinois.

CoOper, I. S. \& HoEN, T. I. (I952). Neurology, 2, 322.

Gerstmann, MAX (I926). Quoted by Bors \& Comarr (I960).

Jousse, A. T., Macdonald, Margaret \& Wynn-Jones, Megan (I964). Paraplegia, 2, I 46. Jung, H. \& SChMidt, K. (I962). Zbl. Gynäk., 84, i IO5.

Robertson, D. N. Struan \& Guttmann, Ludwig (i963). Proc. roy. Soc. Med., 56, 38r. TAlbot, Herbert S. (I955). F. Urol., 73, 9 I. 